ADALAH : Buletin Hukum \&

Keadilan

Buletin Hukum \& Keadilan

@adalahuinjkt

\title{
Kebebasan Hak Politik Perempuan Dalam Parlemen
}

\author{
Hendi Pramana*
}

Politik merupakan tahapan individu untuk membangun dan membentuk kekuasaan yang ada pada masyarakat yang terstruktur sesuai dengan hasrat yang dimilikinya yang dapat mengubah segala tatanan mengenai kondisi masyarakat. Membicarakan politik memang tidak jauh dari demokrasi, sebab dalam hal pengisian personal anggota parlemen sendiri mesti dilalui dengan tahapan-tahapan pemilihan umum yang notabene pilar demokrasi, sehingga dengannya terekrut wakil rakyat yang dipilih oleh rakyat secara langsung. Rekrutmen wakil rakyat ini akhirnya memperdebatkan persamaan gender dalam berpolitik. Dalam Jurnal Cita Hukum, Nur Asikin Thalib mengatakan bahwa Undang-Undang Nomor 31 tahun 2002 tentang Partai Politik tidak memiliki pengaturan yang prinsipil berkaitan dengan kesetaraan gender. Hal ini memunculkan gerakan dari kelompok feminis yang mengungkap ketidakpuasan mengenai hal tersebut, sehingga lahirnya Undang-Undang Nomor 2 tahun 2008 sebagai media hukum baru yang dinilai lebih revolusioner dan berpihak kepada hak politik kaum perempuan (Thalib, 2014: 234)

Politik yang didominasi oleh laki-laki membuat hak wanita terabaikan, sehingga diupayakan persamaan hak antar laki-laki dan perempuan. Hal yang

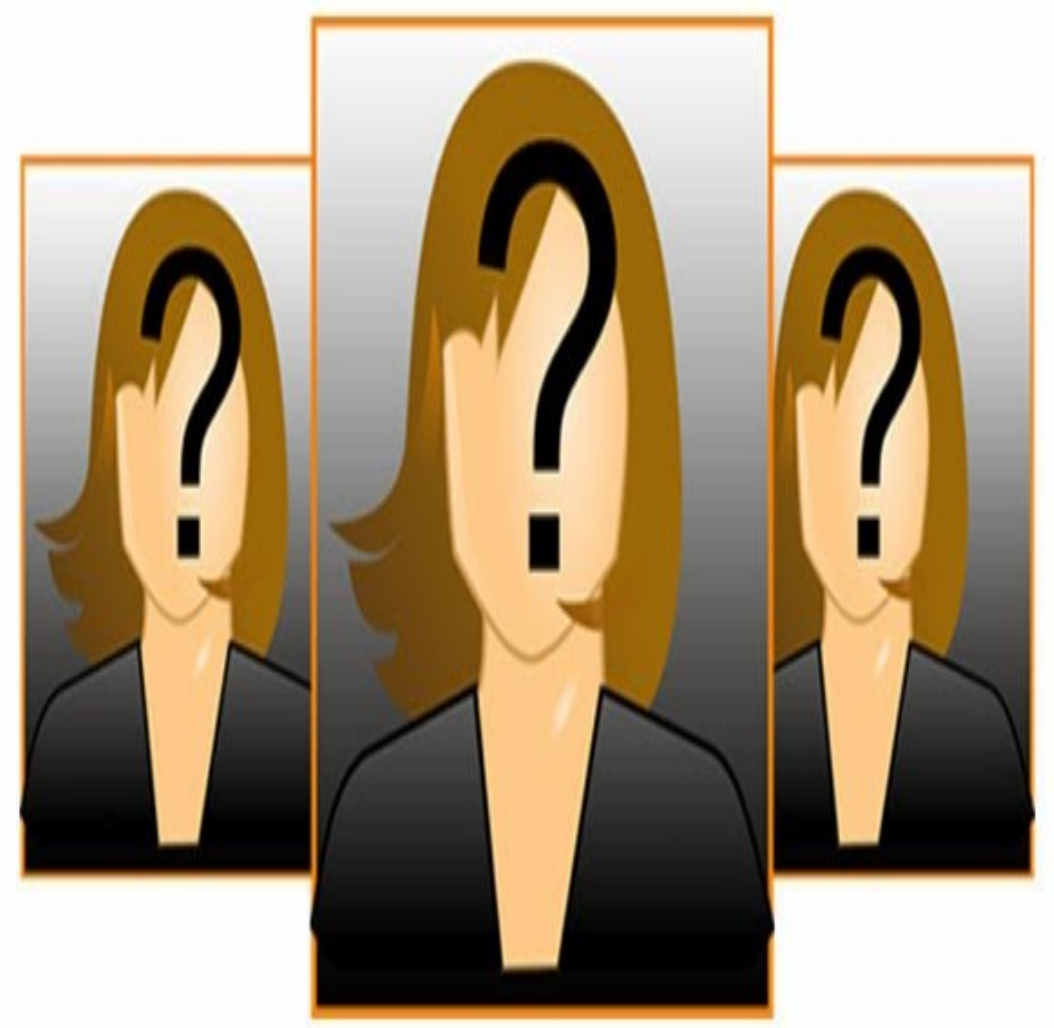

mempengaruhinya adalah Nilai sosial budaya atau adat yang ada pada masyarakat. Bahwasannya seorang wanita tidak hanya mengerjakan hal yang berhubungan dengan rumah dan dapur, tetapi juga hak politik untuk duduk sebagai wakil rakyat di parlemen, serta turut serta direkrut oleh partai politik yang ada. Dengan adanya Undang-undang Nomor 2 tahun 2008 ini, demokrasi kembali hidup dan hasil demokrasi ketatanegaraan Indonesia pun berwujud lembaga legislatif yang tidak bias gender. Implikasinya, adanya keterwakilan perempuan di parlemen tentu berpengaruh pada peningkatan mutu dalam pengambilan keputusan-keputusan politik penyelenggara negara, sehingga tercipta integrasi bangsa yang kokoh dalam bingkai Negara Kesatuan Republik Indonesia (Zada, 2015: 27). Walau pun perempuan yang menjadi anggota DPR RI baru masuk sekitar 3,8\% dari banyak jumlah peserta, namun setidaknya 
dapat mempengaruhi kondisi sosial perempuan di masyarakat, dan aspirasi-aspirasi dari kalangan perempuan dapat sampai kepada kursi parlemen, seperti halnya kebutuhan-kebutuhan dasar perempuan dapat terperhatikan lebih baik dan maksimal lagi.

Nur Asikin Thalib mengatakan dalam jurnalnya bahwa kondisi masyarakat perempuan mengalami keadaan terpuruk yang salah satu faktornya adalah kebijakan yang tidak berpihak padanya, sehingga mendesak pemerintah untuk membuat langkah khusus guna mencapai keadilan dan kesetaraan gender. Finalnya, lahirlah Undang-Undang Nomor 12 tahun 2003 tentang Pemilihan Umum yang turut memperhatikan

keterwakilan perempuan sebanyak $30 \%$ dari calon DPR, DPRD Provinsi dan DPRD Kota/Kabupaten (Thalib, 2014: 237).

$\begin{array}{lr}\text { Namun, } & \text { dengan } \\ \text { segala } & \text { kebanggaan } \\ \text { gerakan tersebut berhasil } \\ \text { dan mendorong jumlah } \\ \text { angka }\end{array}$
wanita di parlemen pada tahun 2004 sampai dengan 2009, tetapi harapan akan hal ini tidak berlangsung lama disebabkan tiadanya keharusan bagi partai politik dan tidak ada sanksi bagi parpol yang melanggar, apabila tidak dapat memenuhi kuota

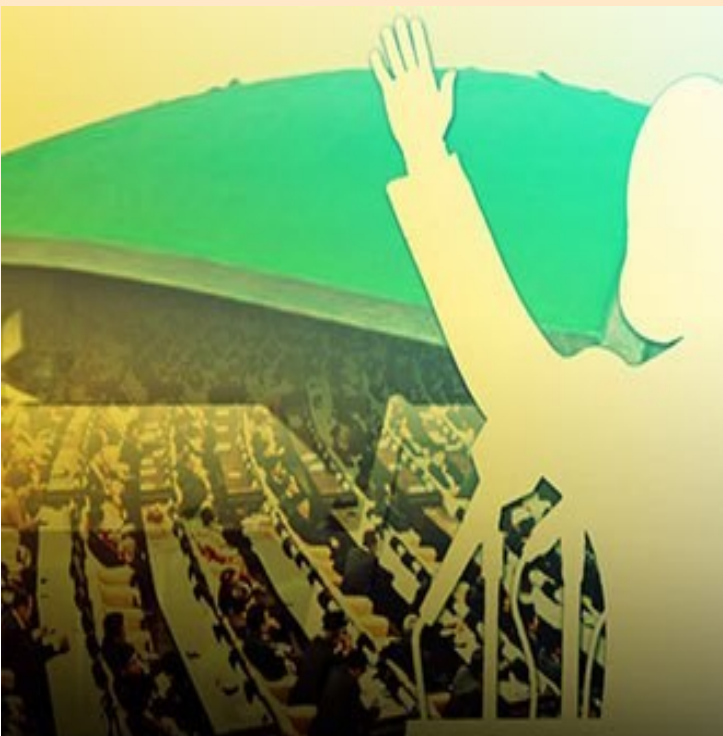
perempuan Indonesia mempunyai kekuatan yang kuat akan hak-haknya, sehingga dapat sama dan sejajar dengan kaum lelaki. Faktor nilai budaya masyarakat maupun kendala dalam lapangan politik serta persaingan dengan laki-laki serta keaktifan yang minim dalam kepengurusan partai politik jangan dijadikan sebagai alasan baru pengurai hak-hak politik kaum perempuan yang sudah terayomi ini. Karenanya dibutuhkan political will dari pihak terkait, termasuk Komisi Pemilihan Umum yang mampu mengeluarkan aturan untuk mengakomodasi semangat affirmative action tersebut, sehingga terwujud politik perempuan dalam memperjuangkan hak politik kaumnya.[] keterwakilan perempuan. Penyebabnya karena adanya kata "dapat" pada Undang-Undang Nomor 12 tahun 2003 yang lama. Selain itu menempatkan calon legislatif wanita kepada bagian bawah memliki potensi banyak suara pada nomor caleg dan jumlah kouta yang ditentukan tidak sesuai dengan apa yang seharusnya, sehingga menimbulkan ketidakadilan dalam pemungutan suara, dan Mahkamah Konstitusi pun perlu meninjau kembali Undang-Undang Nomor 12 tahun 2003 tersebut agar hak dari individu untuk dipilih harus dilindungi yang sebagai Negara yang menganut sistem demokrasi.

Landasan berpikir mengangkat hak politik kaum

\section{Daftar pustaka}

*Penulis adalah anggota Criminal Law and Justice Community (CLJC) dan mahasiswa HPI FSH UIN Syarif Hidayatullah Jakarta.

Thalib, Nur Asikin. "Hak Politik Perempuan Pasca Putusan Mahkamah Konstitusi," Jurnal Cita Hukum, Vol. 2, No 2, (2014).

Zada, Khamami. "Kewenangan Legislasi Dewan Perwakilan Daerah Dalam Reformasi Kelembagaan Perwakilan Pasca Putusan Mahkamah Konstitusi," Jurnal Cita Hukum, Vol. 3, No. 1, (2015).

'Adalah; Buletin Hukum dan Keadilan merupakan berkala ilmiah yang diterbitkan oleh Pusat Studi Konstitusi dan Legislasi Nasional (POSKO-LEGNAS), Fakultas Syariah dan Hukum UIN Syarif Hidayatullah Jakarta.

Penasehat: Prof. Dr. H. Abdul Ghani Abdullah, SH., Prof. Dr. H. A Salman Maggalatung, SH., MH. Pemimpin Redaktur: Indra Rahmatullah, Tim Redaktur: Nur Rohim Yunus, Fathuddin, Mara Sutan Rambe, Muhammad Ishar Helmi, Erwin Hikmatiar. Penyunting: Indah Furba, Hasin Abdullah. Setting \& Layout: Siti Anisaul Kamilah. 